\title{
Modeling of wind actions at wind-tunnel and Russian building codes and regulations
}

\author{
Fedosova Anastasia N. ${ }^{1, a}$ \\ ${ }^{1}$ Moscow State University of Civil Engineering, 129337, Yaroslavskoe sh., 26, Moscow, Russian \\ Federation \\ amgsu@broll.ru
}

Keywords: Aerodynamics, book review, wind actions, building codes, physical modeling, wind-tunnel.

\begin{abstract}
This paper analyzes the Russian and foreign scientific and technical, regulatory, methodological framework affecting the scientific and technical problem of modeling the impact of wind on buildings and structures to identify key requirements for such testing and modern world trends. In the paper, an analysis of domestic and foreign regulations. The modern scientific-technical and methodological framework for simulation of wind effects, existing in Russia is being analyzed.
\end{abstract}

\section{Introduction}

A modern architecture is no longer a unified: the trend leads to a complication of shapes and space-planning solutions for buildings and structures and to an increasing their altitude. All this leads to the fact that modern buildings and structures often have complex geometries for which the unknown values of the various factors, which required for the appointment of the estimated wind loads on structures, when for such buildings wind loads may be decisive.

Design and construction of buildings of original architectural forms and designs is constrained by the applicable regulatory and regulated procedures, which do not contain recommendations for the purpose of wind settlement for buildings of a similar class, and offer facilities for such tests be guided by the results of large-scale layout in specialized wind tunnels. Despite the fact that the earliest attempts to simulate the effect of wind on buildings dated 18th century - model moved in an air flow and measured resistance, an idea to fix the model and move the liquid or gas (water or air) occurred in the 19th century - such experiments were performed under air flow with low turbulence and the boundary layer is not modeled, and the need for modeling the surface boundary layer led to the creation of gradient wind tunnel in the middle of the 20th century; the regulatory framework governing this area are currently not sufficiently developed.

\section{Russian building codes and regulations}

Currently, the calculation of wind farms on the territory of the Russian Federation is regulated by the following codes:

1) Building code 20.13330.2011 «Loads and action. The updated edition of Building code 2.01.07-85» [1];

2) Moscow City Building Code 4.19-05. «Moscow. Multifunctional high-rise buildings and complexes» [2];

3) Territorial Building Code 31-332-2006. «St. Petersburg. Residential and public high-rise buildings» [3];

4) Guidance Documents for Construction 20-1.2006 «Interim recommendations for loads and impacts of destination, acting on a multifunctional high-rise buildings and complexes in Moscow» (Date of update: 12/02/2016) [4].

The main document of Russian designer [1] contains the analytical methods of calculation of buildings and structures on the wind for the simple shape of typical buildings. For buildings of 
complex architectural forms, high-rise building complex geometry, structures elevated levels responsibility Building code [1] recommends determination of wind loads by using physical testing of large-scale models in wind tunnels of a special type, but the test method itself, the requirements for the testing carried out or references to the relevant regulations are missing.

However, since the beginning of the 90s of the last century the typical architecture gave way to atypical ant at the territory of the Russian Federation a lot of high-rise buildings with non-standard geometric forms and solutions began to appear, while appropriate regulatory documentation for the calculation of wind loads on buildings was absent; despite the fact that such buildings due to mold and have a complex altitude aerodynamics and are more vulnerable to wind loads.

Due to the above-described problem, in 1995, by the decision of the Government of Moscow Moscow City Building Code 4.19-05 «Moscow. Multifunctional high-rise buildings and complexes» [2] was developed.

Current recommendation proposed using the test results of high-rise buildings models in specialized wind tunnels with a gradient flow for buildings higher than 75 meters, during the simulation existing adjacent building should be taken into account.

Similarly [2] at [3] methodology for conducting tests of this kind, or references to the relevant regulations are missing.

In 2006, "LenNIIProject OAO (open joint-stock company), St. Petersburg, developed territorial building code "Residential and public high-rise buildings" [4], which is a normative documents in St. Petersburg construction.

These standards apply to the design of residential and public buildings up to $150 \mathrm{~m}$ (residential buildings higher than $75 \mathrm{~m}$, public buildings - more than $50 \mathrm{~m}$ ), as well as complexes of buildings. The regional norms of St. Petersburg like [2] indicate a need for aerodynamic testing for high-rise buildings because of their sophisticated aerodynamics, as in the previous documents, the test procedure is absent.

At the end of 2006 in the Kucherenko Central Research Institute of Building Constructions an attempt to update existing regulatory methods for the design of multi-functional high-rise buildings and complexes was taken: "Interim guidance on loads and impacts purpose, acting on a multifunctional high-rise buildings and complexes in Moscow" (Guidance documents for construction) was developed [4].

Like [2] and [3] document [4] for such type of buildings requires the appointment of aerodynamic coefficients by physical modeling results. However, unlike [2] and [3], [4] though doesn't itself contain the test methods, but gives the major requirements for aerodynamic model tests, namely:

- Compliance with the aerodynamic similarity criteria;

- Modeling general location plan within $\mathrm{r} \geqslant \mathrm{h}$ ( $\mathrm{h}$ - the height of the building);

- The similarity of basic dynamic properties;

- Simulation of the turbulent structure of the actual wind conditions, including the vertical gradient of the mean wind speed and energy spectrum of the fluctuating component of it. This requirement is feasible only in a tube with a long working area.

Thus, operating in the territory of the Russian Federation normative documents indicated the need for the appointment of the calculated wind loads on the building atypical by aerodynamic experimental data, but the actual test procedure is completely absent. Requirements for physical testing in wind tunnels are the following: the need to create a gradient flow, accounting enclosing building, compliance with the criteria of aerodynamic similarity and dynamic similarity and the wind tunnel must have a long working area.

\section{Modern trends in the field of research in Russia}

Currently, the problem of modeling of wind effects on the territory of the Russian Federation are engaged in the organization and laboratories equipped with wind tunnels: Zhukovsky Central Aero-Hydrodynamic Institute (TsAGI), Moscow region; Unicon, Novosibirsk; Krylov State Research 
Centre, St. Petersburg; Lomonosov Moscow State University (MSU), Moscow; Moscow State University of Civil Engineering (MGSU), Moscow. Krylov State Research Centre in St. Petersburg specializes at shipbuilding.

TsAGI has the largest experimental base and specializes at aerodynamics flying devices and aerospace equipment, although it has works at building aerodynamics. In [5] existing regulatory requirements [4] in terms of aerodynamic tests deemed as insufficient and proposed to add the document a number of additional requirements: to modeling parameters of the external flow, the surrounding buildings, wind tunnel type, to the test itself and to received during those tests results [5].

The author considers incorrect static idea of "power" velocity profile above the level of development. Ditto for multihull skyscrapers must take into account the phenomenon of buffeting - a special kind of aerodynamic instability, is not reflected in [4]. In [5] states that the transverse dimension of the model when tested in low-speed wind tunnel (less than $50 \mathrm{~m} / \mathrm{s}$ ), can not be less than $0.05 \mathrm{~m}$. The author points to the need to provide a wind tunnel turntable. During the work the author comes to a conclusion about the need for a methodology for testing of buildings and structures in the wind tunnel [5]. The author considers incorrect static idea of "power" velocity profile above the level of development. As for multihull high rises the phenomenon of buffeting - a special kind of aerodynamic instability, is not reflected in [4], should be taken into account. Work [5] indicates that the transverse dimension of the model when tested in low-speed wind tunnel (less than $50 \mathrm{~m} / \mathrm{s}$ ) can not be less than $0.05 \mathrm{~m}$. The author points to the need of providing a wind tunnel turntable. During the work the author comes to a conclusion about the need for a creation a testing methodology for of buildings and structures in the wind tunnels [5].

Unicon has been researching the aerodynamics of buildings and structures since 1970. Unicon gradient wind tunnel has a cross-section of $1.5 \times 2.0 \mathrm{~m}$ and a length of $17.5 \mathrm{~m}$. Special attention should be paid to "The Atlas of aerodynamic coefficients" [6] of 2003. In [6] the aerodynamic coefficients for bodies that are not contained in the rules [1] are given: the physical body and elliptic cylindrical forming - wire, ropes, masts; spherical and hemispherical body; trusses; Orthodox churches; covering buildings and so forth. The impact of the fairings on the aerodynamic coefficients is shown [6].

The Mechanics Research Institute of MSU conducts experiments at subsonic speeds, using a wind tunnel with cross-section area of 7,32 $\mathrm{m}^{\wedge} 2$ and working area length of $4 \mathrm{~m}$. Works at Architecture and Construction Research MSU are carried out in collaboration with Moscow State University of Civil Engineering. In [7] - [9] questions of wind loads simulation on the building envelope are raised. Research in the field of computer modeling of wind effects [10], [11] is being conducted. The influence of the terrain on the aerodynamics of buildings [12] is being observed.

MGSU Laboratory of aerodynamic and aeroacoustic tests of building structure (AAISK) is the youngest, it was established in 2008. AAISK is equipped with a unique wind tunnel architectural and construction type with working area more than $15 \mathrm{~m}(18,9 \mathrm{~m})$. Despite the short time of laboratory existence, for 6 years since the establishment AAISK has accumulated extensive experience in the study of aerodynamics building structures.

Research on the development and improvement of methods of experimental research in the wind tunnel architectural and construction types, including design and construction of models of unique buildings and structures [13] is being conducted, as well as bridge structures [14], and the methodology of experimental modeling of wind effects [15], [16]. Research on the development of numerical methods [17], [18] and computational and experimental methods for modeling wind effects on buildings and structures [19] is being carried out.

\section{Summary}

Regulatory documents operating abroad contain much more information than domestic. Although they do not contain, as such most, experimental procedure; however specified requirements as to the testing purpose, and to test themselves, including wind tunnels, where these demands considerably 
higher and formulated clearer than in domestic: this choice and requirements for scale atmospheric turbulence; requirements to specifications; need retention blocking coefficient within 10\%; keeping pressure gradient and the frequency characteristics of the tube itself, stringent requirements for measuring equipment; justification for choice of correct scale speed; requirements for adjustment of boundary layer and etc..

But Russian tasks and tasks of advanced countries in the field of aerodynamics of buildings and structures today are different. While foreign countries engaged in improving existing at each laboratory aerodynamic testing techniques, the primary task of Russia is the elimination of regulatory information vacuum on the part of an experimental study of the aerodynamics of buildings and structures.

\section{Acknowledgements}

This work was financially supported by the Council for Grants of the President of the Russian Federation for state support of young Russian scientists in the framework of the research MK6194.2015.8.

\section{References}

[1] Building code 20.13330.2011 «Loads and action. The updated edition of Building code 2.01.07-85».

[2] Moscow City Building Code 4.19-05. «Moscow. Multifunctional high-rise buildings and complexes».

[3] Territorial Building Code 31-332-2006. «St. Petersburg. Residential and public high-rise buildings».

[4] P.G. Clem, M. Rodriguez, J.A. Voigt and C.S. Ashley, U.S. Patent 6,231,666. (20 Guidance Documents for Construction 20-1.2006 Interim recommendations for loads and impacts of destination, acting on a multifunctional high-rise buildings and complexes in Moscow (Date of update: 12/02/2016).

[5] Airapetov A.B. New aspects of the aerodynamics of wind loading of high-rise buildings in the city, new approaches and methodological principles of research as the source of the concept of the formation of new standards of design and construction // Construction Science. №3, 2010. Pp. 582584.

[6] Berezin M.A, Katyushin V.V. Atlas V. The Atlas of aerodynamic coefficients. Novosibirsk, 2003.

[7] Gagarin V.G., Guvernyuk S.V. and Looshin K.I. Simulation of fiber emission from mineral wool insulation curtain façade system with ventilated layer // Industrial and civil construction, number 9, 2013. Pp. 27-29.

[8] Gagarin V.G., Guvernyuk S.V. and Ledenev P.V. Aerodynamic performance of buildings for the calculation of wind effects on the building envelope // Housing construction, №1, 2010, Pp. 7-11.

[9] Gagarin V., Guvernyuk S.V. and Ledenev P.V. The calculation of the wind effect on the lining curtain facade systems in accordance with Russian standards, the UK, Holland, USA and Eurocode // ACADEMIA. №3, 2010. Pp. 157-160.

[10] Gagarin V., Guvernyuk S.V. and Kubenin A.S. About the reliability of computer predictions in determining wind effects on buildings and complexes //: Housing construction. №7, 2014. Pp. 3-8.

[11] Gagarin V., Guvernyuk S.V., Kubenin A.S. and Sinyavin A.A. Questions of application of modern computer technology to solve practical problems of building aerodynamics // Herald of the 
Department of construction of the Russian Academy of Architecture and Building Sciences. Vol.18, 2014. Pp. 151-156.

[12] Isaev S.A., Egorychev O.O., Guvernyuk S.V. and Kornev N.V. Architectural and construction Aeromechanics high-rise buildings, taking into account the terrain and the selection of wind energy // Vestnik of St. Petersburg State University. 2012. Pp. 1-7.

[13] Churin P.S., Poddaeva O.I. and Egorychev O.O. Designing layouts of unique buildings and structures in experimental aerodynamics // Scientific and Technical Gazette Volga. 2014. № 5. Pp. 332-335.

[14] Egorychev O.O., Churin P.S. and Poddaeva O.I. Design and manufacture of bridge aeroelastic model for aerodynamic experiments // Scientific Review. 2015. № 9. Pp. 111-114.

[15] Egorychev O.O., Churin P.S. and Poddaeva O.I. Experimental study of silo-torque wind loads on tall buildings // Industrial and civil construction. 2014. № 9. Pp. 28-30.

[16] Poddaeva O.I., Buslaeva Y.S. and Gribachev D.S. Experimental study of wind loads on high-rise multi-residential complex // Vestnik of the Belgorod State Technological University. VG Shukhov. 2014. № 6. Pp. 58-62.

[17] Poddaeva O.I., Dubinsky S.I. and Fedosova A.N. Numerical simulation of aerodynamics of high rise building // Industrial and civil construction. 2014. № 9. Pp. 23-27.

[18] Kubenin A.S. and Fedosova A.N. Numerical simulation of aerodynamics of a residential complex with adjoining buildings // Scientific Review. 2015. № 8. Pp. 136-141.

[19] Poddaeva O.I. and Dunichkin I.V. Computational experimental studies of wind effects for residential complexes in Moscow // Industrial and civil construction. 2016. № 4. Pp. 42-45. 